\title{
A HISTÉRICA E AS BELAS, RECATADAS E DO LAR: MISOGINIA À DILMA ROUSSEFF NA CONCEPÇÃO DAS MULHERES COMO COSTELAS E DOS HOMENS COMO CABECA DA POLÍTICA BRASILEIRA
}

\author{
- JANAÍNA DE FÁTIMA ZDEBSKYI' \\ - EDUARDO MEINBERG DE ALBUQUERQUE MARANHÃO² \\ - JOANA MARIA PEDRO
}

\begin{abstract}
Resuma: Apresentamos, neste artigu, algumas reflexões acerca dos ataques miś́ginos perpetrados à primeira presidenta da Brasil, Dilma Rousseff, que, atualmente safrenda processo de impeachment, fai substituída por um governo interino que, assim como parte dos veículas midiáticas do país, representa uma concepçãa conservadora do papel da mulher na politica e saciedade brasileira. Este padrão ideal de mulher, de acorda com visão reacionária, pode ser sintetizada pela expressão "belas, recatadas e do lar", enquanto Dilma, a quem se quer criticar a visão política ou o governo, recebe adjetivos como "feia, histérica e vadia".
\end{abstract}

Palavras-chave: Dilma Rousseff e misaginia; Michel Temer e conservadarismo; gênero, religiãa, mídia e política.

Introdução

Apresentamos neste artigo $^{4}$, algumas considerações acerca do papel que as mulheres brasileiras deveriam desempenhar na política brasileira em algumas concepções conservadoras. Nestas, as mulheres deveriam estar mais restritas ao espaço privado, ou, se participando de alguma forma do espaço público, especialmente do político, circunscreverem-se ao protagonismo masculino. E, em algumas destas concepções, caso ocupem um cargo mandatário de altíssima proeminência, 
como no caso da Presidenta da República Dilma Rousseff, o fato dela ser mulher reverberaria como justificativa para críticas relacionadas à condução de seu governo.

Este artigo se divide nas seguintes partes: inicialmente, faremos algumas considerações preliminares sobre a participação das mulheres brasileiras na política, para em seguida comentarmos acerca da misoginia sofrida pela primeira presidenta do Brasil, Dilma Rousseff, que, sofrendo processo de impeachment, foi substituída interinamente por um governo marcado por um "masculinistério" - ou um ministério formado apenas por homens. Estas partes, indiciárias de um ideal reacionário que privilegia o protagonismo masculino, são complementadas por outro tópico, que procura demonstrar como a mulher pode ser entendida metaforicamente (e aludindo a versos bíblicos) como costela do homem, sendo este o cabeça da relação - inclusive das relações políticas. Por fim, apresentaremos algumas considerações ao final, feitas em um momento em que políticas públicas estão sendo lamentavelmente extintas pelo governo interino de Michel Temer, substituto provisório de Dilma Rousseff.

\footnotetext{
Breve histórico da participação das mulheres brasileiras na política
}

A participação das mulheres na política brasileira em pleno século XXI, fenômeno recente, visto que o sufrágio universal em nosso país só se deu no século XX, é ainda bastante reduzida e enfrenta diversos preconceitos e limitações.

Anteriormente às primeiras décadas do século XX, eram diversos os argumentos que impediam as mulheres de votar e de serem votadas, expressando uma concepção masculinista de família em que a mulher era "a rainha do lar", também propagando os princípios dos "sagrados" deveres femininos, considerados incompatíveis com qualquer participação na esfera pública (DUARTE, 2003). Confinadas à esfera do lar e ao cuidado da família,

a educação das mulheres concentrava-se na preparação para o seu destino último: esposas e mães. Mesmo os homens brasileiros que se consideravam progressistas e que aprovavam a igualdade universal proclamada pelo Cristianismo', acreditavam que o objetivo da educação feminina era a preparação para a maternidade. Basicamente, as meninas deveriam aprender a cuidar bem de suas casas, pois lhes cabia a obrigação de garantir a felicidade dos homens. Todavia, 
alguma educação era bem acolhida, pois se tornariam melhores mães para os filhos e melhores companheiras para os maridos. Embora o homem tradicional e progressista assumissem juntos que as mulheres pertenciam ao lar, o segundo admitia ampliar o papel da mulher na família, enfatizandolhe o poder de orientar moralmente suas crianças e fornecer bons cidadãos ao país. (HAHNER, 2003, p. 123-124 apud BARBOSA; MACHADO, 2012, p. $92)$.

Nessa perspectiva estava impregnada a teoria da incapacidade $d a$ mulher, que concebia que as mulheres eram emotivas e instáveis, e que sob pressão pública não conseguiam tomar decisões racionais. Além disso, esta teoria supunha que a inaptidão feminina na esfera pública era natural e não cultural, e reforçava que as mulheres eram inferiores aos homens com base em princípios formulados no âmbito interpretativo masculino. As imposições dessa teoria só foram superadas quando as feministas brasileiras se apropriaram dos conhecimentos científicos e argumentações do campo social e cultural (BARBOSA; MACHADO, 2012).

A conquista do voto feminino em todo o mundo não se deu ao acaso, foi resultado de grandes lutas e reinvindicações do movimento feminista. No Brasil, foram diversos os nomes de mulheres que protagonizaram a luta pelo direito ao voto nas primeiras décadas do século XX. Berta Lutz, por exemplo, uma grande líder sufragista brasileira, aglutinou um grupo de mulheres da burguesia para financiar voos sobre a cidade do Rio de Janeiro com o intuito de espalharem panfletos pedindo o voto feminino, além de pressionar deputados federais e senadores e se dirigirem ao presidente Getúlio Vargas (BLAY, 2001; e DUARTE, 2003). Bertha foi incansável ao promover discursos e textos inflamados e denunciando a opressão das mulheres. Com outras companheiras, fundou a Federação Brasileira pelo Progresso Feminino, que se disseminou em praticamente todos os Estados brasileiros (DUARTE, 2003).

Mesmo diante da visibilidade das reinvindicações e de um movimento feminista organizado, a luta pelo voto feminino enfrentou diversos entraves. Em 1932, com o Código Eleitoral Provisório e o Decreto $\mathrm{n}^{\mathrm{o}}$. 21.076, algumas mulheres passaram a ter direito a voto. As condições eram, no caso de mulheres casadas, que tivessem permissão do esposo, e se solteiras ou viúvas, que possuíssem renda própria, o que demonstra que o voto 
feminino era limitado e dependente de condições econômicas ou da vontade dos maridos (BARBOSA; MACHADO, 2012).

A conquista do direito ao voto para todas as mulheres só se consolidou em 1934, com grande parcela de protagonismo da Federação Brasileira pelo Progresso Feminino. Além disso, as mulheres passaram também a ter o direito de serem votadas (BARBOSA; MACHADO, 2012). Entretanto, considerando a suspensão das eleições decretada por Getúlio Vargas, o exercício do voto feminino só veio a ser colocado em prática em 1945 (BLAY, 2001; e DUARTE, 2003).

Mesmo depois de protagonizarem protestos e reinvindicações, de se apropriarem de conhecimentos científicos e argumentações proficientes, as mulheres ainda continuaram, e de certo modo continuam, à margem da participação política no Brasil. Aliás, é bom realçar que, não só a participação das mulheres no cenário político do país ainda se mostra frágil e cheia de entraves como também a própria democracia brasileira demonstra sua incipiência e instabilidade: um exemplo está na recente, cruel e virulenta ditadura, fruto de golpe militar, a que o país foi submetido entre 1964 e 1985, e que traz reflexos execráveis na atualidade, como as posturas reacionárias de grande parte de nossos/as parlamentares, que tem gradualmente imputado um verdadeiro retrocesso aos direitos humanos e às liberdades arduamente conquistadas pela população, especialmente pelos setores mais vulneráveis politicamente da mesma, como as mulheres, a comunidade transgênera, a comunidade nãoheterossexual, as pessoas indígenas, negras e quilombolas, dentre outras.

Nessa história recente e quebradiça da democracia brasileira, foi somente em 2010 que uma mulher foi eleita ao cargo de Presidenta da República. Dilma Rousseff foi a primeira mulher brasileira eleita presidenta - e gostaríamos de frisar: president $a, \operatorname{com} a, \mathrm{e}$ não presidente.

\section{De Dilma Rousseff, uma presidenta com "a" no final - e alvo de (in)tensa misoginia - a Michel Temer e seu "masculinistério"}

Mesmo enfrentando diversas resistências por estar no lugar de mulher, divorciada, militante contra a ditadura iniciada em 1964 e representante do Partido dos Trabalhadores (PT), costumeiramente considerado um partido de esquerda, Dilma Rousseff se elege como presidenta da república em 2014, e 
desde os primeiros meses de seu mandato seu governo começa a enfrentar ataques não só políticos, mas também misóginos da mídia e dos partidos e parlamentares de oposição ao governo.

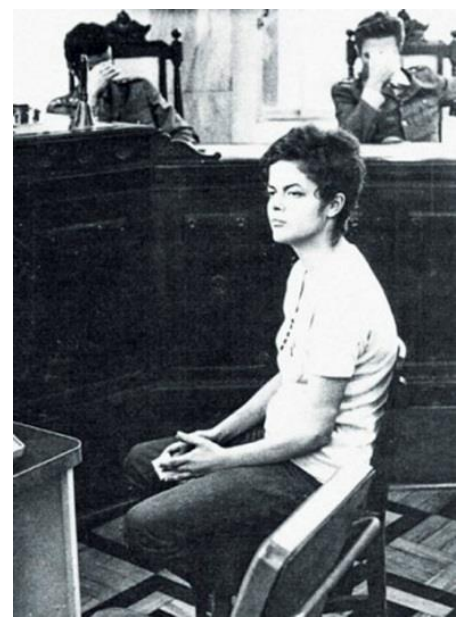

Foto de Dilma Rousseff prestando depoimento quando capturada na ditadura militar na década de 1970. Foto: Reprodução - Justiça Militar. Disponível em: http://www 12.senado.leg.br/jornal/edicoes/2015/01/02/dilm a-da-oposicao-ao-regime-militar-a-presidencia-da-republica $>$

Um possível exemplo da resistência à figura de Dilma como presidenta está na reação de diversos setores da mídia e da política, que insistiram que a mesma deveria ser chamada pelo masculino (ou neutro) presidente - em alguns casos simplesmente por entender que presidente é termo neutro, e em outros, por intentarem de alguma forma $o$ apagamento da identidade política e feminina do termo presidenta. Por outro lado, e que aqui advogamos, o uso de presidenta com a no final dá força ao simbolismo e representatividade das mulheres no mais alto cargo da política brasileira. Cabe ressaltar que o vocábulo presidenta não foi sugerido por Dilma, mas já constava em dicionários, como afirma o linguista Marcelo Módolo. Para este,

$$
\begin{aligned}
& \text { embora pareça recente, } \\
& \text { "presidenta" é termo antigo. Ao } \\
& \text { menos desde o dicionário de } \\
& \text { Cândido de Figueiredo (1899): } \\
& \text { "Presidenta, f. (neol.) mulher que } \\
& \text { preside; mulher de um presidente. }
\end{aligned}
$$
(Fem. de presidente.)" "Presidenta" já está consignado no Vocabulário Ortográfico da Língua Portuguesa (Volp), no Houaiss; por isso, para mim, é indiferente o uso - diz Módolo (PEREIRA JUNIOR, 2011).

Até mesmo no âmbito da linguagem foram proferidos ataques à figura de Dilma e ao que ela representa: uma mulher em um espaço de poder público. Isso se expressa pelas últimas notícias a respeito das ações do governo interino de Michel Temer em vetar o uso da palavra "presidenta" em publicações da Empresa Brasileira de Comunicação (EBC). Essa informação foi divulgada pelo jornal Online "Brasil 247" o qual, no dia 31 de maio de 2016, noticiou que

Sob as novas regras do governo interino de Michel Temer 
(PMDB-SP), a Empresa Brasileira de Comunicação (EBC) deixou de usar a termo "presidenta", para se referir à presidente afastada Dilma Rousseff (PT). O uso do feminino da palavra era uma exigência de Dilma, para marcar o fato de ter sido a primeira mulher a assumir a Presidência da República, no país. A mudança teve início na semana passada, quando os funcionários receberam orientação para mudar a forma de tratamento do cargo no feminino, tanto na televisão quanto na agência de notícias Brasil. "Por orientação da gerência executiva, informamos que a TV Brasil passa a adotar a forma presidente, independente do gênero. Deixamos, portanto, de usar presidenta”, informa email enviado aos jornalistas. A EBC confirmou a mudança e disse que o dois termos podem ser aplicados uma vez que tem previsão nas normas da língua portuguesa. "Sendo assim a EBC decidiu utilizar a terminologia presidente para adequar à linguagem que vem sendo praticado pelos demais veículos de comunicação do país”, diz em nota (BRASIL 247, 2016).

Se falar ou não presidenta não demonstra necessariamente misoginia, as interpelações feitas à Dilma ao criticá-la são mais sintomáticas: muitas pessoas, ao se referirem a ela, utilizam interpelações como puta, vadia, feia e bruxa. Ora, algum político brasileiro, desses "com o saco roxo”, e também alvo de controvérsias e/ou de críticas políticas acaso seria chamado de puto, vadio, bruxo ou feio ao sofrerem críticas?

Aliás, a expressão ter o saco roxo refere-se a um conjunto de atributos relacionados à virilidade e masculinidade, considerados, em algumas concepções, relevantes à condução de um país. A expressão foi popularizada por Fernando Collor de Mello, ex-presidente da República, em 1991. Collor sofreu impeachment por conta das denúncias comprovadas de corrupção de seu governo, e, ao contrário de Dilma, nunca foi feita nenhuma menção à sua masculinidade - ou ao seu suposto saco roxo - como justificativa dá má condução de sua administração.

Um exemplo dos ataques misóginos-midiáticos se expressa na capa da revista ISTOÉ, que infere: "Em surtos de descontrole com a iminência de seu afastamento e completamente fora de si, Dilma quebra móveis dentro do Palácio, grita com subordinados, xinga autoridades, ataca poderes constituídos e perde (também) as condições emocionais 
para conduzir o País" ${ }^{5}$. O discurso desse texto perpetua as ideias da "teoria da incapacidade da mulher" esboçada anteriormente, colocando Dilma como emocionalmente instável e por isso inapta a ocupar uma função na vida pública, a de dirigir o país como presidenta.

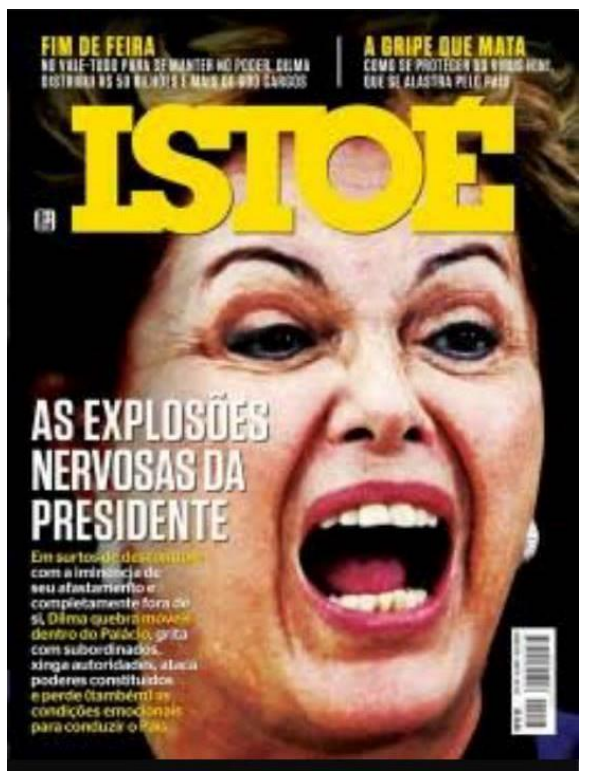

Imagem da Capa da Edição 2417 (abril de 2016) da Revista ISTOÉ

Para além de reportagens misóginas que contestam a capacidade de governabilidade de Dilma Roulseff com argumentos que a colocam como desequilibrada e instável, observamos também campanhas como a utilização de adesivos nos quais Dilma aparece de pernas abertas. Tais adesivos, criados como crítica ao aumento do combustível no primeiro semestre de 2015, eram colados na abertura dos tanques do carro onde a mangueira de combustível é inserida, fazendo uma metáfora a uma penetração vaginal na presidenta e por consequência uma violação simbólica ao seu corpo e, de alguma forma, uma analogia à prática do estupro.

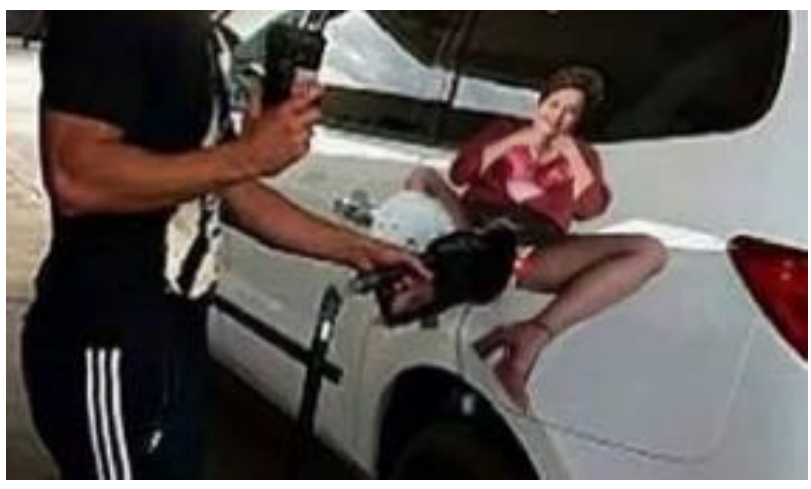

Veja São Paulo (01 set. 2015). Anúncio de adesivo com montagem de Dilma foi feito por uma mulher. Disponível em: <http://vejasp.abril.com.br/blogs/cidade/adesivo-com-montagemde-presidente-dilma-causa-revolta-na-internet/>

Segundo a Veja São Paulo,

Uma mulher é a autora dos anúncios sobre adesivos com uma montagem da presidente Dilma Rousseff. A informação, publicada pelo jornal Folha de S.Paulo nesta quinta (9), foi repassada pelo site Mercado Livre, onde havia sido publicado o material, à Secretaria de Política para Mulheres. A anunciante, que é de Recife, de acordo com o jornal, afirmou que seu ex-marido usou a conta dela no site para postar as imagens.

A revista Veja, na reportagem supracitada, e a Folha de S. Paulo, na matéria original, buscam desviar o foco do machismo e da misoginia presentes na figura do adesivo, argumentando que o 
mesmo teria uma mulher como autora, como se esse fator amenizasse a violência explicita na utilização do adesivo ou como se o fato deixasse de se configurar como misoginia e machismo.

As redes sociais também vêm se configurando como um grande campo de disputa de narrativas e de ataques misóginos constantes à Dilma. Dentre as diversas páginas que de alguma forma abordam a pessoa de Dilma, temos a "comunidade" de facebook "FORA DILMA", dentre as características da página está a foto de perfil onde é colocada uma caricatura de Dilma apenas com o contorno do rosto, o desenho do cabelo e os dois dentes da frente em destaque e para fora, expressando um destaque à característica física considerada fora dos padrões sociais de beleza. Além disso, no campo "Sobre", onde está a descrição das informações da página consta o texto "Chega! O Brasil acordou! Você não me representa PresidentE! FORA DILMA!", com destaque na letra "E" da palavra presidente para expressar a resistência em utilizar o termo no feminino "presidenta", bem como já foi debatido no inicio deste artigo.

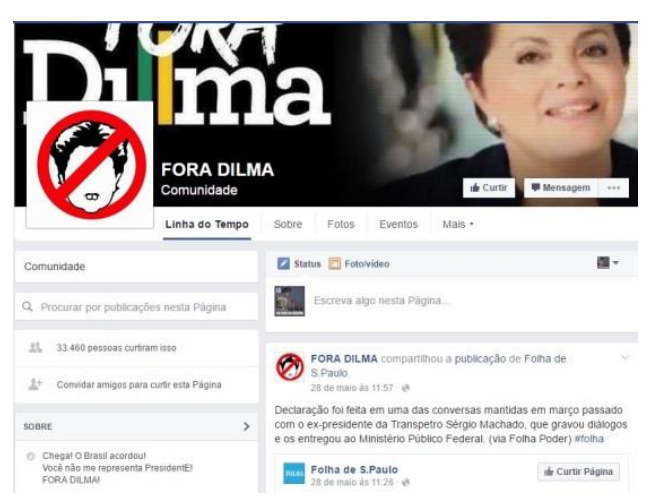

Imagem da "comunidade de facebook FORA DILMA". Disponível em https://www.facebook.com/ForaDilmaAmazonas/info/?tab=p age info

Ainda no que se refere aos ataques proferidos à Dilma por meio do Facebook, podemos encontrar comunidades e grupos públicos (foto abaixo) que se referem a ela como "vagabunda". Em um dos grupos, com 244 membros, com o nome "Campanha!!! Fora Dilma vc é uma vagabunda!!!!" (foto abaixo), o criador do grupo aparentemente um adolescente - posta uma notícia falsa a respeito de uma medida de Dilma para suspensão de Redes Sociais e logo abaixo coloca o seguinte comentário: "melhor nao falar isso nao, do jeito q essa vagabunda sem noção é, e perigoso essa puta fazer isso msm”, em seguida o menino é repreendido por uma mulher que diz que suas palavras são muito pesadas para um adolescente de 14 anos a qual ele responde dizendo que "A dilma vai continuar sendo vagabunda .!.”, sendo que o símbolo ao final do 
comentário do menino significa mostrar o dedo do meio da mão.

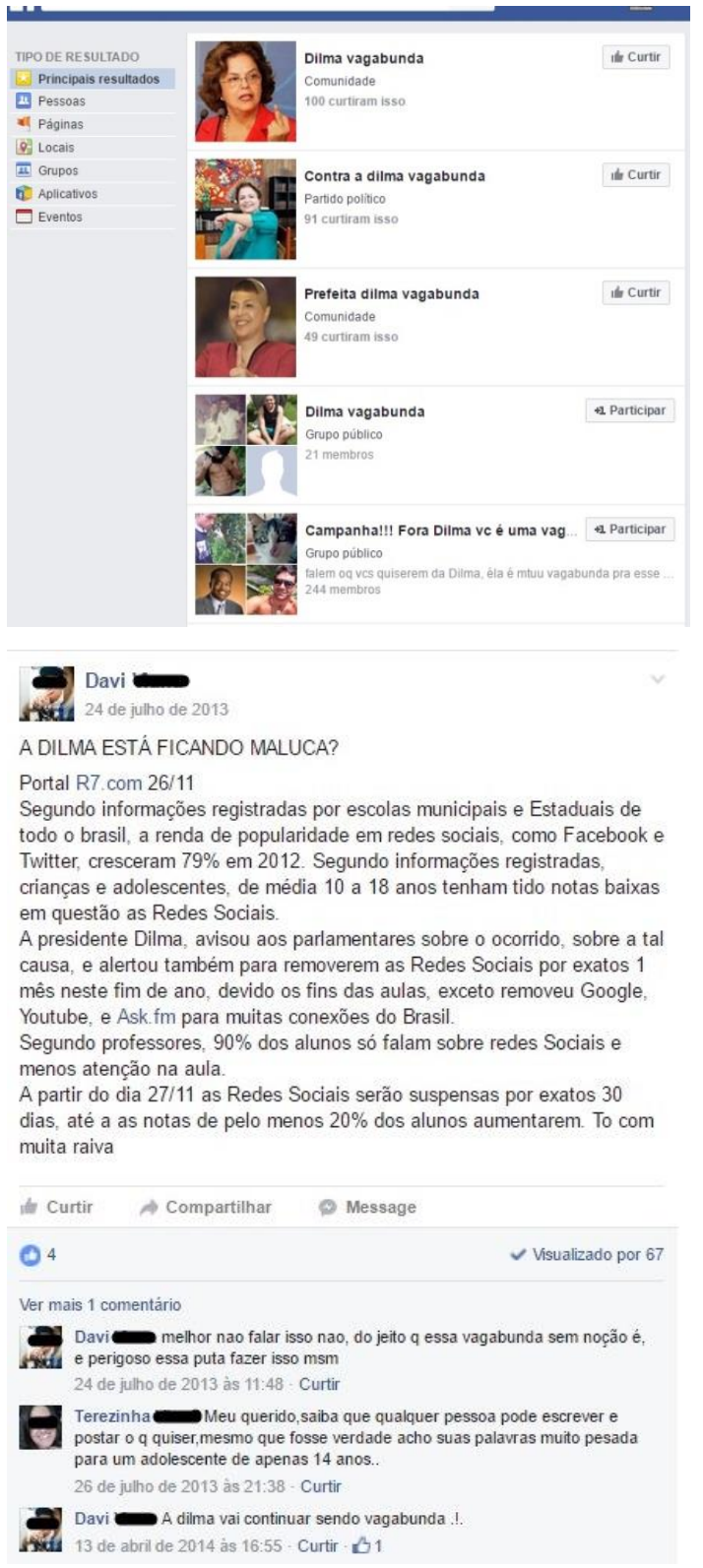

Imagem de resultados de busca no Facebook por "Dilma Vagabunda" e imagem de postagem no grupo "Campanha!!! Fora Dilma vc é uma vagabunda!!!!". Disponível em <https://www.facebook.com/groups/1401923183353274/?fref $=\mathrm{ts}>$

Esses ataques midiáticos e dos mais diversos setores fundamentalistas e conservadores se estendem até 12 de maio de 2016, que certamente se configura como data histórica para a democracia brasileira. Nesse dia, foi aprovado no Senado por 55 votos a 22 o afastamento da presidenta eleita Dilma Rousseff por até 180 dias, abrindo assim o processo de impeachment sobre seu mandado. Para compreender alguns aspectos que permeiam o afastamento de Dilma é preciso retomar o contexto da votação ainda no Congresso Nacional no dia 17 de abril de 2016 e abordar algumas falas de justificativa de votos proferidas pelos deputados federais presentes que foram favoráveis à abertura do processo de impeachment:

Marco Feliciano (PSC-SP): "Com ajuda de Deus, pela minha família e pelo povo brasileiro, pelos evangélicos da nação toda, pelos meninos do MBL, pelo Vem pra Rua, dizendo que Olavo tem razão, dizendo tchau para essa querida, e dizendo tchau ao PT, partido das trevas, eu voto sim!" Fabio Sousa (PSDB-GO): "Pela minha família! Meus filhos, Estevão, Amanda, pela minha esposa, pelos meus pais, pelo meu estado de Goiás, pelo futuro do Brasil, eu digo sim!"

Delegado Waldir (PR-GO): "Pátria Amada! Pátria Amada! Seu filho Delegado Waldir não foge à luta! Pelo meu país, por Deus, por 
minha família, pelas pessoas de bem. Meu voto é sim! Fora Dilma, fora Lula, fora PT!"

Takayama (PSC-PR): "Contra a ladroeira, contra a imposição e a esquerda desse partido que quer transformar esse Brasil numa ditadura de esquerda, por Sergio Moro, pelo Paraná, pela minha família!"6

As falas apresentadas são de alguns dos deputados federais que votaram "sim" na seção que provou a abertura do processo de impeachment por 367 votos favoráveis e 137 votos contrários, tendo 7 abstenções $\quad$ e $\quad 2$ ausências. O conteúdo dessas justificativas de voto é representativo da grande maioria das falas dos deputados que se colocaram como favoráveis na votação, sendo que em seus discursos podemos perceber referências marcantes e repetitivas à Deus e à família (pais, esposas e filhas/os), principalmente presentes nas falas dos deputados ligados à partidos que compõem as bancadas BBB (da Bíblia, do Boi e da Bala). Em algumas destas falas, como a do pastor-deputado Marco Feliciano, conhecido por suas posturas misóginas, racistas e LGBTfóbicas, o PT é referido como partido das trevas, aludindo à histórica demonização do "comunismo" e seu voto, ajudado por Deus, é dedicado aos evangélicos de toda a nação e a indivíduos e setores reacionários como Olavo de Carvalho e o Movimento pelo Brasil Livre (MBL).

Além da referência "tchau, querida”7, feita por Feliciano, muitos parlamentares seguraram faixas e cartazes com os mesmos dizeres. "Dar tchau a esta querida" se insere em um contexto masculinista, sexista e misógino em que grande parte dos/as parlamentares brasileiros/as são representantes pautados pela desqualificação política "justificada” no fato da pessoa ser mulher. Um deputado claramente articulado a tais falas e às bancadas acima citadas, Jair Messias Bolsonaro (PSC/RJ), proferiu uma fala ainda mais perniciosa, na mesma sessão da Câmara:

Nesse dia de glória para o povo tem um homem que entrará para a história nesta data pela forma como conduziu os trabalhos da casa. Parabéns presidente Eduardo Cunha (vaias e aplausos). Perderam em 64, perderam agora em 2016. Pela família e pela inocência das crianças em sala de aula que o PT nunca teve, contra o comunismo, pela nossa liberdade, contra o Foro de São Paulo, pela em memória do coronel Carlos Alberto Brilhante Ulstra, o pavor de Dilma Rousseff, pelo Exército de Caxias, 
das nossas Forças Armadas, por um Brasil acima de tudo e por Deus acima de todos, o meu voto é sim. ${ }^{8}$

Bolsonaro

refere-se, semelhantemente a Feliciano, a Deus, a setores e indivíduos reconhecidamente reacionários e recalcitrantes à promoção de políticas públicas, à família (obviamente aquela do comercial de margarina, formada por pai, mãe e filha/os, excluindo outros formatos possíveis), à infância em sala de aula (remetendo à suposta "ideologia de gênero" e ao "kit gay", ao qual Bolsonaro se colocou contra há alguns anos e que supostamente seria oferecido nas escolas com o intuito de "converter crianças ao homossexualismo"), ${ }^{9}$ e ao "comunismo" (como se tivesse havido alguma tentativa de implantação do mesmo no Brasil pelo PT). Além disso, se refere diretamente a Eduardo Cunha, que naquele momento presidia a sessão mesmo sendo réu do STF, às Forças Armadas, e ao coronel Carlos Alberto Brilhante Ulstra, que foi chefe do Destacamento de Operações de Informação - Centro de Operações de Defesa Interna (DOI-CODI), de São Paulo, órgão especializado em serviços de repressão do governo ditatorial iniciado em 1964. Em sua fala, Bolsonaro refere-se a Ulstra como "pavor de Dilma Rousseff", remetendo às sessões de tortura que afligiram a presidenta durante os anos de chumbo brasileiros.

Dilma sempre expressou publicamente as repercussões psicológicas negativas que as torturas sofridas na ditadura militar causaram em sua vida, sendo que a fala de Bolsonaro não se configura como a primeira vez em que a questão da ditadura foi utilizada como forma de ataque à Dilma, mesmo quando ela ainda não havia chegado no cargo de presidenta da república, mas já ocupava importantes espaços na política. Em 2008 quando Dilma prestava depoimento à Comissão de Infra-estrutura do Senado enquanto ministra-chefe da Casa Civil, o senador José Agripino Maia pelo DEM do $\mathrm{RN}$ que afirmou que Dilma disse ter durante a ditadura "ao lembrar de seus tempos de cadeia", afirmação a qual Dilma deu a seguinte resposta:

Qualquer comparação entre a ditadura militar e a democracia brasileira, só pode partir de quem não dá valor a democracia brasileira. Eu tinha 19 anos, eu fiquei três anos na cadeia e eu fui barbaramente torturada, senador. E qualquer pessoa que ousar dizer a verdade para interrogadores compromete a vida dos seus iguais, entrega pessoas para serem mortas. Eu me orgulho muito de ter mentido senador, porque 
mentir na tortura não é fácil. Agora, na democracia se fala a verdade, diante da tortura quem tem coragem e dignidade, fala mentira. $\mathrm{E}$ isso senador faz parte e integra a minha biografia que eu tenho imenso orgulho. $\mathrm{E}$ eu não estou falando de heróis, feliz do povo que não tem heróis desse tipo senador, porque aguentar tortura é algo dificílimo, porque todos nós somos muito frágeis, todos nós... nós somos humanos, nós temos dor e a sedução, a tentação de falar o que ocorreu e dizer a verdade é muito grande senador, a dor é insuportável. O senhor não imagina o quanto é insuportável. Então eu me orgulho de ter mentido, eu me orgulho imensamente de ter mentido porque eu salvei companheiros da mesma tortura e da morte (...) Não tenho nenhum compromisso com a ditadura em termos de dizer a verdade, eu estava num campo e eles estavam no outro, o que estava em questão era minha vida e a de meus companheiros. Não há verdade, não há espaço pra verdade e é isso que mata, o que mata na ditadura é que não há espaço pra verdade porque não há espaço pra vida senador, porque algumas verdades, até as mais banais podem conduzir a morte, é só errarem a mão no seu interrogatório, e eu acredito senador que nós estávamos em momentos diversos da nossa vida em 70, eu tinha entre 19 e 21 anos e de fato eu combati a ditadura militar e disso eu tenho imenso orgulho. ${ }^{10}$

Sendo assim, esses ataques, especialmente a referência a Ulstra, geraram diversas reações da sociedade, inclusive em redes sociais como o Facebook. Por um lado, houve reações favoráveis, expressas no largo aumento de pessoas curtindo as fanpages tanto de Ulstra (falecido em 15 de outubro de 2015) como de Bolsonaro, e de outro, milhares de pessoas criticando tal alusão em seus perfis. Associações de pessoas historiadoras (assim como de outros campos de conhecimento) como a Associação Nacional de História (ANPUH) e a Associação Brasileira de História das Religiões $(\mathrm{ABHR})^{11}$ se posicionaram publicamente em repúdio a tais declarações de Bolsonaro, assim como contra o golpe parlamentar / jurídico / midiático que se encontra em curso.

Os parlamentares de bancadas evangélicas, como é o caso de Jair Bolsonaro e Marcos Feliciano, ambos do PSC, têm em curso um projeto fundamentalista, e de acordo com Eliane 
Moura da Silva (2006) esse projeto tem por inimigos mais temidos $\mathrm{e}$ vigorosamente atacados o feminismo $\mathrm{e}$ emancipação das mulheres, considerados como "doença, degeneração, causa dos males do mundo, uma filosofia da morte, do medo, do pecado, do perigo, da raiva e da violência” (MOURA, 2006, p. 18). Para a autora, os fundamentalistas consideram que o papel das mulheres cristãs seria o de lutar contra esses males, além de reconduzir seus maridos ao centro dos acontecimentos e salvar os filhos, a família e a sociedade; para isso, a família e o fortalecimento dos papéis tradicionais de gênero ganham estatuto de espiritualidade, fé e militância. A mesma autora ainda destaca que nesses papeis tradicionais de gênero coube "aos homens o mandado divino de exercer autoridade sobre mulheres e crianças. Deus comanda os homens da mesma maneira que o poder masculino comanda as mulheres $\mathrm{e}$ as crianças" (SILVA, 2006, p. 19), para exemplificar, ela cita a afirmação de Schaeffer (2000):

É maravilhoso ter um pai que é uma rocha, uma fortaleza, uma defesa contra ataques, um conselheiro, um abrigo contra os inimigos. É maravilhoso ter uma mãe que pode se concentrar no ensino, sendo sensível às necessidades da criança, compassiva, aconchegante e carinhosa, capaz de criar um ambiente especial no lar, enquanto serve as refeições, cuida das roupas e faz algumas das outras coisas relacionadas em Provérbios 31. (...) É importante ensinar aos meninos que um dia você vai ser pai que vai amar e cuidar dos seus próprios filhinhos. Precisamos ensinar às meninas que é maravilhoso ser mãe (...). Enquanto o papai fica fazendo outras coisas para preparar um lar para o bebê ficar feliz e depois poder aprender, a mamãe fica livre para ter o bebê crescendo dentro dela (SCHAEFFER, 2000, p. 52 apud SILVA, 2006, p. 19).

Considerando essas concepções fundamentalistas, fica explicito que nesse projeto que visa a manutenção dos papéis tradicionais de "homem" e "mulher" o lugar da mulher é confinado ao ambiente doméstico, ao lar e aos cuidados dos filhos e da família. Além de se configurar como um projeto fundamentalista que tem por sustentação a manutenção dos valores morais ligados à composição cis/heteronormativa de família única - e à repressão de qualquer tipo de desvio dessa configuração familiar entendida como tradicional - é preciso reconhecer que, 
nesse sentido, esse cenário é também um projeto patriarcal que em sua essência tem por objetivo confinar as mulheres à esfera privada, distante dos espaços políticos, de poder e de decisão que há séculos são dominados pelos homens.

Entendemos que o patriarcado se configura enquanto um discurso normativo de papéis familiares, considerando, primeiramente, que a associação entre famílias e patriarcado remete à origem, já opressora, do termo "família" que significa "escravo doméstico", visto que na Roma Antiga a família romana era centrada no homem e o patriarca tinha sob seu poder a mulher, os filhos, os escravos e os vassalos, além do direito de vida e de morte sobre todos eles. É importante considerar que o patriarcado não designa o poder do pai, mas o poder dos homens, ou do masculino, enquanto categoria social. O patriarcado é uma forma de organização social na qual as relações são regidas pelo princípio de que as mulheres estão hierarquicamente subordinadas aos homens (NARVAZ; KOLLER, 2006).

A predominância de uma organização social patriarcal se estende até a contemporaneidade com aquilo que entendemos por um "patriarcado moderno”, em que as mulheres ainda estão submetidas aos homens tanto na esfera privada quanto na pública (Bernardes, 1995; Hileshiem, 2004; Narvaz, 2005; Szymanski, 1997 apud NARVAZ; KOLLER, 2006), considerando ainda que estudos com famílias brasileiras

apontam estereótipos acerca da divisão do trabalho dentro do ambiente doméstico de acordo com o sexo da pessoa e demonstram a tradicional distinção entre os papéis do pai e o da mãe na chamada família nuclear, formada pelos pais e seus filhos dependentes. O papel da mãe ainda remete ao cuidado dos filhos, enquanto o papel do pai, além de prover o sustento, envolve questões de disciplina e de autoridade. A responsabilidade pelas tarefas domésticas e pelo cuidado dos filhos é predominantemente feminina, trabalho (re)produtivo ocultado, negligenciado e desvalorizado pelo contexto social. Embora a participação dos homens nas famílias pobres seja precária, persiste o modelo do homem como provedor financeiro e de autoridade. O papel das mulheres no sustento econômico é invisibilizado e desqualificado, legitimando a crença de que o homem é o legítimo provedor da família, "o que confere uma 
posição de trabalhadora complementar à mulher, embora os fatos da realidade revelem que as mulheres trabalhadoras muitas vezes são as reais provedoras do sustento familiar” (Fonseca, 2000, p.46 apud NARVAZ; KOLLER, 2006, p. 52).

Relacionam-se a isso pesquisas recentes, como a relativa à tolerância social à violência contra as mulheres, realizada pelo IPEA em 2014, é demonstrado que as imposições colocadas na Lei $\mathrm{n}^{\circ} 4.121$ de 27 de agosto de 1962 que dispunha sobre a vida da mulher casada e determinava em seu Artigo 233 que "O marido é o chefe da sociedade conjugal" - ainda não foram superadas, ou seja, realmente vivenciamos uma configuração de patriarcado moderno na qual o homem ainda se coloca como "chefe da família”. Para além disso, a pesquisa deixa claro que explicitamente vivenciamos uma cultura do estupro em nosso país, onde a vitima é culpabilizada por sofrer violência, o estupro é banalizado e suas causas atribuídas às roupas, aos comportamentos e hábitos da vitima em uma tentativa de desresponsabilizar o agressor pelas suas

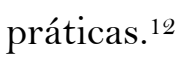

As expressões dos ideais patriarcais, machistas, masculinistas e cis/heteronormativos, vistos por exemplo no processo de abertura do impeachment de Dilma não estão presentes somente nas votações referidas anteriormente. Tal coisa é também perceptível no primeiro dia do governo interino (que xs autorxs deste texto entendem como ilegítimo) de Michel Temer (PMDB), que decreta, através da medida provisória $\mathrm{n}^{\circ} 726$, a extinção do Ministério das Mulheres, da Igualdade Racial e dos Direitos Humanos e do Ministério da Cultura. Aos ministérios restantes o presidente interino nomeia apenas ministros homens - o que poderia valer o apelido de "masculinistério", dada a não-representatividade feminina.

Para as mulheres, restaram apenas algumas secretarias subordinadas a ministérios, conforme declaração do ministro-chefe da Casa Civil, Eliseu Padilha, na sexta-feira 13 de maio de 2016 - matéria feita por Felipe Amorim; Leandro Prazeres e Ricardo Marchesan (2016) para o UOL notícias -, de que "o governo do presidente interino Michel Temer terá mulheres em secretarias, postos "com as mesmas atribuições" de ministérios", segundo Padilha.

As práticas do governo inteiro de Michel Temer também vêm se expressando como ataques às mulheres brasileiras, considerando que devido à exclusão do Ministério das Mulheres, da 
Igualdade Racial e dos Direitos Humanos passamos a ter uma Secretaria de Políticas para Mulheres. Nesse sentido, é também relevante considerar que a secretária nomeada - a ex-deputada federal Fátima Pelaes (PMDB-AP) - é uma mulher evangélica que não concorda com a descriminalização do aborto e se coloca contra o procedimento inclusive em casos de estupro, o que é permitido por lei desde 1984 em nosso país. Trata-se assim de um retrocesso. O site do Grupo de Pesquisa Mídia, Religião e Cultura do programa de Pós-Graduação em Comunicação da Universidade Metodista de São Paulo (UMESP), sob edição da professora Magali do Nascimento Cunha, escreveu, no dia 02 de junho de 2016, uma matéria a respeito desse assunto na qual afirma que Fatima Pelaes "não levanta bandeiras contrárias aos valores bíblicos, como o aborto e a constituição livre de família”.

Essa postura da nova gestora da Secretaria de Políticas para Mulheres se apresenta como um grave retrocesso na conjuntura atual, considerando que recentemente ocorreu um caso de estupro coletivo onde, no dia 21 de maio de 2016 , uma adolescente de 16 anos foi estuprada por 33 homens em uma comunidade da Zona Oeste do Rio de Janeiro, esse caso se tornou uma polêmica em todos os veículos de comunicação e redes sociais nacionais.
Sobre isso, no dia 02 de junho de 2016, o mesmo informativo da UMESP afirmou que uma pesquisa no perfil social dos 33 acusados desse estupro coletivo teria revelado que 14 deles se identificam como evangélicos. Sob esse aspecto, a antropóloga Adriana Dias (2016) que fez a investigação das redes sociais desses homens afirma que todos que encontrou eram evangélicos de diversas denominações e problematiza:

os evangélicos radicais têm todo o interesse em desconstruir a imagem da vítima (alegando que ela é imoral e "devassa”) porque isso, teoricamente, fortaleceria o argumento de que estudo religioso é necessário nas escolas e provaria que eles sabem resolver problemas melhor que o pessoal dos Direitos Humanos", explica Adriana. "No entanto, se esse tipo de moralização fosse eficiente, o que explicaria que todos os homens que encontrei envolvidos são evangélicos? (DIAS, 2016).

Essa questão da marginalização das mulheres no âmbito da política também vem se expressando na exclusão de conquistas históricas, como pela já citada extinção do Ministério das Mulheres, da Igualdade Racial e dos Direitos Humanos, dentre outros ataques que vêm sendo forjados na conjuntura 
atual e no "masculinistério" de Michel Temer.

No lugar de uma "feia, puta e histérica", uma "bela, recatada e do lar”: o ideal reacionário da mulher na política como costela e não como cabeça

Ainda sobre a questão da participação das mulheres na atual conjuntura política, é possível perceber que o cenário remonta o do século passado onde as mulheres estavam confinadas à esfera do lar e dos cuidados para com a família. Isso fica explícito na reportagem produzida pela Revista Veja de 18 de abril de 2016, pela colunista Juliana Linhares. A reportagem em questão já anunciava como concreta a possibilidade de Michel Temer assumir a presidência da república e nesse sentido se referia diretamente a esposa de Temer, Marcela Temer, tendo como título "Marcela Temer: bela, recatada e "do lar"”: "A quase primeira-dama, 43 anos mais jovem que o marido, aparece pouco, gosta de vestidos na altura dos joelhos e sonha em ter mais um filho com o vice". Além de já explicitar no título o conteúdo patriarcal da reportagem o discurso do texto posterior coloca que
Marcela Temer é uma mulher de sorte. Michel Temer, seu marido há treze anos, continua a lhe dar provas de que a paixão não arrefeceu com o tempo nem com a convulsão política que vive o país - e em cujo epicentro ele mesmo se encontra. Há cerca de oito meses, por exemplo, o vicepresidente, de 75 anos, levou Marcela, de 32, para jantar na sala especial do sofisticado, caro e badalado restaurante Antiquarius, em São Paulo.” (...) Marcela é uma vice-primeira-dama do lar. Seus dias consistem em levar e trazer Michelzinho da escola, cuidar da casa, em São Paulo, e um pouco dela mesma também (nas últimas três semanas, foi duas vezes à dermatologista tratar da pele) (...) Em todos esses anos de atuação política do marido, ela apareceu em público pouquíssimas vezes. "Marcela sempre chamou atenção pela beleza, mas sempre foi recatada", diz sua irmã mais nova, Fernanda Tedeschi. "Ela gosta de vestidos até os joelhos e cores claras", conta a estilista Martha Medeiros (LINHARES, 2016)

O conteúdo da reportagem coloca o perfil "bela, recatada e do lar" como o ideal para o comportamento de uma mulher e enaltece a forma de se vestir de 
Marcela Temer como o que seria correto para uma mulher decente ou recatada. Além disso, dá relevância ao fato de Marcela se dedicar quase que exclusivamente aos cuidados da casa e da família e coloca-a como sendo uma mulher de sorte, considerando a vida de luxo e acesso a bens materiais que Temer lhe proporciona.

Além da revista Veja, O Jornal de Brasília na edição impressa do dia 16 de maio de 2016, na coluna de Gilberto Amaral, coloca o seguinte texto: "Várias críticas foram feitas ao governo do presidente Temer pela falta de uma mulher à frente de um ministério. Por si só a beleza de sua mulher, Marcela (foto), como primeira-dama do país, já representa muito bem o charme e elegância da mulher brasileira (AMARAL, 2016).”

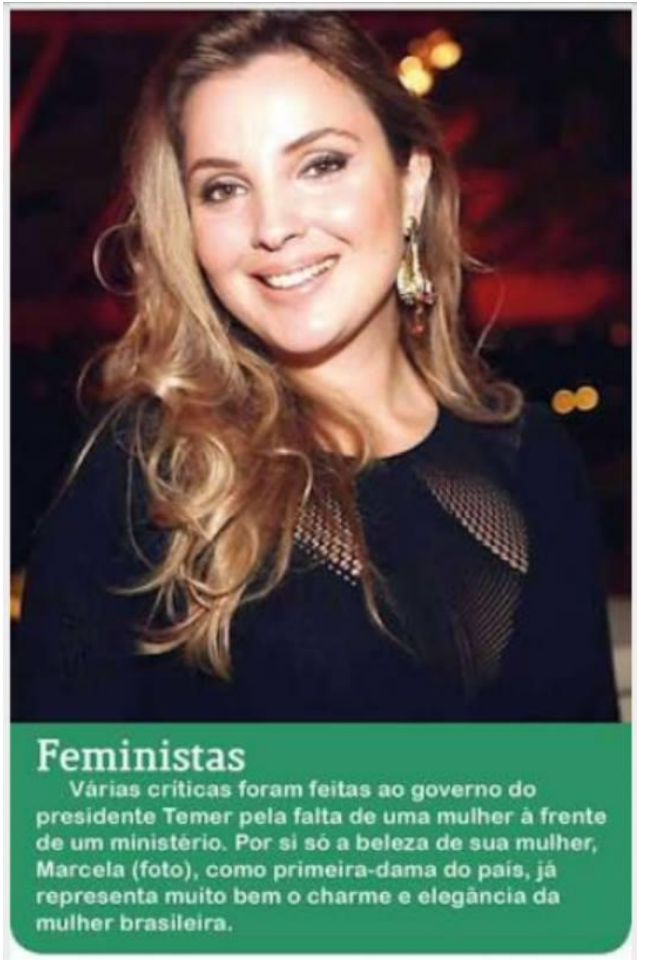

Imagem da reportagem do Jornal de Brasília

Tanto a reportagem da Revista Veja quanto a do Jornal de Brasília deixam explícito que o lugar ideal para a mulher na sociedade brasileira é aquele representado por Marcela Temer, uma mulher dedicada à família, bela, de vestes decentes e elegante, demonstrando também que o lugar ideal a uma mulher no mais alto cargo da nação é o de primeira-dama e não o de presidenta da República, visto que a função de uma presidenta está em visível contradição com o papel de uma mulher recatada e do lar - o que possivelmente remete a determinado padrão bíblico, aquele em que a mulher é vista como costela do homem, que por sua vez, é o cabeça da relação - e 
nestes termos, Marcela seria a costela de Temer (e talvez a costela da nação), enquanto este seria o cabeça de Marcela e do país, ou talvez usando outra metáfora, Marcela seria a dobradiça da porta, e Temer, obviamente, a porta. ${ }^{13}$

A percepção da mulher como costela do homem fundamenta-se em versos bíblicos

apropriados para corroborar a dominação masculina no casamento e, em sua maioria, são retirados das cartas de Paulo e do Antigo Testamento. Como exemplos: "multiplicarei grandemente os teus sofrimentos e a tua gravidez; darás à luz teus $\square$ lhos entre dores; contudo, sentir-te-ás atraída para o teu marido, e ele te dominará (Gênesis 3.16)”; "mulheres, sede submissas aos vossos maridos, como convém no Senhor (Colossenses 3.18)"; “os maridos devem permitir que as suas mulheres, que são de um sexo mais frágil, possam orar (I Pedro 3.7)"; "o homem não foi criado pela mulher, mas a mulher para o homem (I Coríntios 11.9)”; “as mulheres devem ficar caladas nas assembleias de todas as igrejas dos santos, pois devem estar submissas, como diz a lei (I Coríntios 14:34)”; “se a mulher trair o seu marido, ela será feita em objeto de maldição pelo Senhor, sua coxa irá descair e seu ventre inchará (Números 5.2027)"; "mulheres, submetei-vos a vossos maridos (Efésios 5.22)”, e um dos mais citados, inclusive na BDN: “a cabeça do homem é Cristo, a cabeça da mulher é o homem e a cabeça de Cristo é Deus (I Coríntios 11.3)”. ${ }^{14}$

Tais versos reverberam interpelações fundamentalistas religiosas, especialmente as direcionadas às mulheres, em que "o jogo de palavras varia entre doçura, mansidão, submissão, poder, força, realização" (SILVA, 2006, p. 23), e ecoam uma "representação central: apresenta-se a mulher subserviente - a costela - e o homem viril, provedor $\mathrm{e}$ dominador - o cabeça da relação" (MARANHÃO $\mathrm{F}^{\circ}$, 2012b, p. 100), ou ainda, aquele de saco roxo, potencialmente bom condutor da nação.

Não é por acaso que muitos destes discursos advem diretamente de pessoas religiosas, algumas delas célebres. A visão da mulher cisgênera e heterossexual como bela, recatada e do lar também pode ser percebida em postagem de Ana Paula Valadão, pastora da Igreja Batista da Lagoinha, de Minas Gerais (foto abaixo), onde a mesma propõe um 
boicote às lojas de roupa $\mathrm{C} \& \mathrm{~A}$, devido à uma propaganda onde homens e mulheres usam as mesmas roupas. $\mathrm{O}$ argumento de Ana Paula Valadão é que isso se trata de "ideologia de gênero", além disso, ela usa as hashtags

\#SouFemininaVistoComoMulher;

\#HomemVesteComoHomem;

\#NãoÁIdeologiaDoGenero;

\#FamíliaÉHomemEMulher;

\#HeteroSexualidade;

\#MonogamiaHeterosexualÉSexoSeguro, dentre outras hashtags que enfatizam seu discurso sexista e heteronormativo.

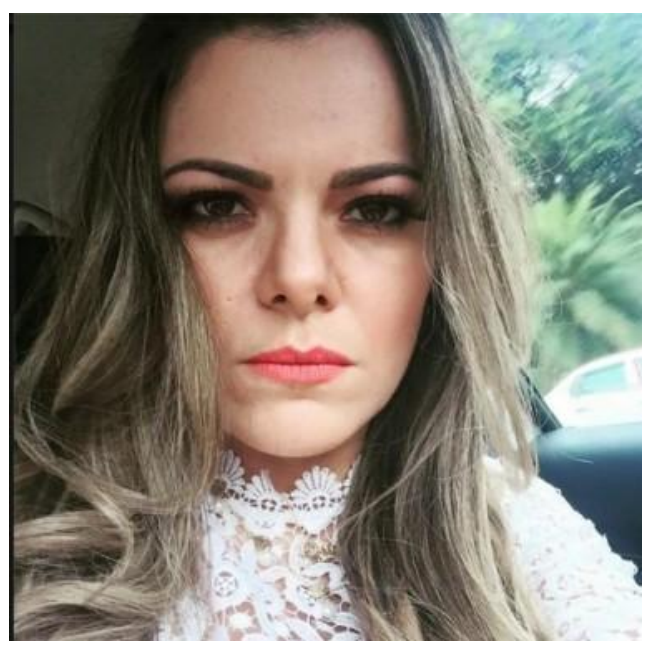

Imagem: Foto da postagem de Ana Paula Valadão

Vale ainda destacar que há também, entre mulheres parlamentares, discursos que dão eco à concepções de gênero binário ${ }^{15}$ envolvendo o papel $d a$ mulher que deve não só prevalecer como existir na sociedade, inclusive nas políticas públicas: a mulher cisgênera. ${ }^{16}$ Dilma assinou, em 28 de abril de 2016, decreto que permitia o uso de nome social a mulheres transexuais, e também a travestis e homens trans - e em 19 de maio, uma deputada que usa um nome social (Tia Eron) assinou, em conjunto com deputados/as de dez partidos, um projeto contra o decreto de Dilma. O pedido para sustar o decreto de Dilma foi protocolado por João Campos, famigerado autor do projeto da "cura gay", apoiado por parlamentares como Marco Feliciano. Tal direito ao uso de nome social, ainda que paliativo, ${ }^{17}$ deveria ser assegurado a tais pessoas, historicamente apagadas e excluídas das políticas públicas. Esta exclusão de direitos se relaciona ao padrão de gênero (binário) que setores reacionários procuram impor à sociedade, como na proposta do projeto Escola sem Partido $^{18}$ e nas discussões que citam uma suposta “ideologia de gênero". ${ }^{19}$

De toda a maneira, as descrições acima apresentadas sinalizam para a reverberação de dois "tipos" de mulher: a histérica, feia e que não é do lar, simbolizada pela presidenta Dilma Rousseff (que também é referida como vadia, puta, comunista e petista das trevas); e as mulheres ideais: belas, recatadas e do lar - costelas dos maridos e/ou da nação.

\section{Considerações em aberto - enquanto} políticas públicas vão se fechando 
Como vimos, está em curso um projeto patriarcal e fundamentalista que visa manter as mulheres confinadas à esfera privada e dedicadas às tarefas de cuidados com a família e educação dos/as filhos/as, um projeto que propaga um perfil de mulher ideal como "bela, recatada e do lar", bem distante dos holofotes da vida pública e dos cargos políticos que ainda permanecem sob domínio masculino de quem tem aquilo roxo.

São diversos os mecanismos de poder envolvidos na consolidação desse projeto, entre eles estão os mandatos de parlamentares que são utilizados para proferir discursos de ódio e saudosismos a torturadores de mulheres na ditadura militar; até a mídia, sejam os jornais, revistas ou as redes sociais; os projetos de lei que visam controlar também o contexto das escolas - espaço de muita importância para formação de pensamento de crianças e adolescentes; além da religião e do apelo aos padrões sociais de beleza que seriam exclusividade de mulheres recatadas e belas, bem diferentes da imagem que é costumeiramente propagada de Dilma Rousseff.

Por fim, importa realçar a posição das pessoas que escrevem este texto de história do tempo imediato: manifestamos aqui nosso repúdio e horror em relação à supressão de direitos humanos, sociais e constitucionais pelo governo interino de Michel Temer, e à misoginia perpetrada à presidenta Dilma Rousseff e a outras mulheres brasileiras que fizeram e fazem parte da vida política desse país.

\section{NOTAS}

1 Mestranda em História pela Universidade Federal de Santa Catarina (UFSC). Bolsista CNPq - Brasil. E-mail: janazdebskyi@gmail.com.

2 Presidente da Associação Brasileira de História das Religiões (ABHR). Pós-Doutorando Júnior em História pela Universidade Federal de Santa Catarina (UFSC). Bolsista CNPq - Brasil. PósDoutor em Ciências Humanas pelo Programa Interdisciplinar da UFSC. Doutor em História Social pela Universidade de São Paulo (USP). Mestre em História do Tempo Presente pela Universidade do Estado de Santa Catarina (UDESC). Pesquisador do Laboratório de Estudos de Gênero e História (LEGH/UFSC). E-mail: edumeinberg@gmail.com.

3 Professora do Programa de Pós-Graduação em História e do Programa de Pós-Graduação Interdisciplinar em Ciências Humanas da Universidade Federal de Santa Catarina (UFSC). Pós-Doutora pela Université d'Avignon. Doutora em História Social pela Universidade de São Paulo (USP). Mestra em História pela Universidade Federal de Santa Catarina (UFSC). Pesquisadora do Instituto de Estudos de Gênero (IEG/UFSC).E-mail: joana.maria.pedro@ufsc.br.

4 Agradecemos a Cristina Scheibe Wolff pelos diálogos acerca do assunto. Realçamos que este trabalho, mais que de história do tempo presente, pode ser considerado de história do tempo imediato, feito no calor dos acontecimentos. Destacamos 
ainda que este texto, opinativo, foi composto de forma apaixonada, motivado pelo momento vivido, e foram utilizados apenas alguns textos da mídia, sem uma exaustiva pesquisa sobre a mídia do momento. Lembramos que a mídia alternativa tem atuado consistentemente no combate ao que se veicula em revistas como Veja e Istoé, por exemplo, e que depois da votação na Câmara, referida no decorrer do texto, várias/os comentaristas da televisão e da imprensa questionaram os votos das/os parlamentares.

${ }^{5}$ ISTOÉ, edição 2417, de 06 de abril de 2016.

6 Transcrições obtidas no site da Folha de São Paulo, na Edição de 14 de abril de 2016.

${ }^{7}$ A expressão se fundamenta no cumprimento final do ex-presidente Luís Inácio Lula da Silva a Dilma Rousseff, em conversa pessoal, gravada sem autorização pelo juiz Sérgio Moro durante investigações da Operação Lava Jato, e propositalmente vazada à imprensa, atitude que pode ser compreendida como arbitrária (ARAÚJO, 2016).

8 Transcrição dxs autorxs deste artigo.

9 Como refere Maranhão $\mathrm{F}^{\circ}$ (2014, p. 435), “em 2010 foi apresentada na Câmara dos Deputados material educativo intitulado "Kit de Combate à Homofobia nas Escolas”, que segundo Jair Ramos, seria o "conjunto de vídeos, boletins e cartilhas que abordavam o universo de adolescentes homossexuais e que buscavam construir uma descrição positiva da homossexualidade como forma de combater o bullying e sofrimento emocional que acompanha os jovens homossexuais na escola” (RAMOS, 2014, s/p). Alguns dias depois, Bolsonaro atacou o material na Câmara: "atenção, pais de alunos de 7, 8, 9 e 10 anos, da rede pública: no ano que vem, seus filhos vão receber na escola um kit intitulado Combate à Homofobia. $\mathrm{Na}$ verdade, é um estímulo ao homossexualismo, à promiscuidade. Esse kit contém DVDs com duas historinhas. Seus filhos de 7 anos vão vê-las no ano que vem, caso não tomemos uma providência agora (Discurso no plenário da Câmara Federal, 30/11/2010, apud RAMOS, 2014, s/p.)”. Tal discurso fomentou um abaixo-assinado no site Petição Pública, endereçado à Presidência da República, e m 25 de maio a presidenta Dilma Roussef vetou o material, negando "ter cedido à chantagem dos deputados evangélicos" e afirmando "sua convicção de que o material do kit estaria mais próximo da apologia à homossexualidade do que à educação contra a homofobia”, o que foi saudado como vitória d@s evangélic@s e como “grande traição por boa parte da militância LGBT” (RAMOS, 2014, s/p).

10 Transcrição de trechos da fala de Dilma Rousseff em vídeo do depoimento, disponível em $<$ https://www.youtube.com/watch?v=Tiyezo $1 \mathrm{fL}$ Rs $>$

${ }^{11}$ Nota de repúdio da ABHR à apologia à tortura em declaração de Jair Bolsonaro: A Associação Brasileira de História das Religiões (ABHR), entidade acadêmica, apartidária e não-confessional / nãoreligiosa, através de sua Comissão de Direitos Humanos, vem reafirmar seu compromisso e função social de apoio à democracia e de respeito à constitucionalidade e legalidade em todos os seus termos. No dia 17 de abril acompanhamos votação na sessão da Câmara Federal que culminou na abertura do processo de impeachment da Presidenta da República, Dilma Rousseff (PT). Consideramos tal processo parte de um golpe político / jurídico / midiático fundamentado em acusações sem provas suficientes de crime por parte da Presidenta. Esta sessão da Câmara; ópera bufa cuja votação foi dirigida por Eduardo Cunha (PMDB), deputado que é réu no Supremo Tribunal Federal (STF); foi ainda negativamente marcada por execrável declaração de um dos seus deputados, Jair Messias Bolsonaro (PSC/RJ). 
Antes de declarar seu voto, o deputado Jair Bolsonaro homenageou / dedicou seu voto à memória do coronel Carlos Alberto Brilhante Ulstra, que foi chefe do Destacamento de Operações de Informação - Centro de Operações de Defesa Interna (DOI-CODI) de São Paulo, órgão de repressão política subordinado ao Exército e especializado em serviços de inteligência e de repressão durante os anos de chumbo do regime ditatorial brasileiro, inaugurado em 1964. Durante sua homenagem, Bolsonaro se referiu ao coronel Ulstra como "pavor de Dilma Rousseff", aludindo aos episódios de tortura sofrida pela mesma. Consideramos que a declaração de Bolsonaro se configura em crime previsto por lei (Art. 287 do Código Penal: "Fazer, publicamente, apologia de fato criminoso ou de autor de crime"). Bolsonaro faz apologia a torturador e à tortura (sendo esta um crime hediondo), e por esta razão, exigimos das autoridades competentes as devidas providências e declaramos nosso mais veemente repúdio a esta declaração. A punição a este parlamentar, entretanto, não é suficiente para deter o golpe que se tenta desferir contra a nossa democracia. As instituições precisam reagir para que o país não entre numa era de obscurantismo e conflitos acentuados pela possível mudança de política sócio-econômica já anunciada pelo líder deste processo de ruptura com a constitucionalidade, o atual vice-presidente Michel Temer (PMDB). Comissão de Direitos Humanos da ABHR, 19 de abril de 2016.

${ }^{12}$ IPEA, 2014, p. 1-40.

${ }^{13}$ MARANHÃO Fo, $2012 b$.

${ }^{14}$ MARANHÃO Fo, 2012 b, p. 99-100.

15 Os discursos binários de gênero, largamente promulgados por parlamentares conservadores/as, muitas vezes se fundamentam em concepções cis/heteronormativas conectadas a pressupostos das áreas psi e a determinadas interpretações bíblicas que entendem as pessoas transgêneras, assim como as pessoas homossexuais e muitas vezes as mulheres, como relacionadas ao pecado ou a influências demoníacas. Tal concepção pode ser chamada provisoriamente de cishet/psi/spi (MARANHÃO $\left.\mathrm{F}^{\circ}, 2014\right)$. Acerca da reverberação de discursos cishet/psi/spi na subjetividade de pessoas transgêneras, leia MARANHÃO Fo, 2014, $2015 a, 2016$.

${ }_{16}$ Cisgeneridade, termo nativo utilizado por parte das pessoas trans* (mas também por pessoas cis), é a condição de quem se sente confortável com as expectativas binárias relacionadas ao sistema sexogênero designado ao nascer ou durante a gestação. Já a transgeneridade seria a condição sócio-política de transgressão de normas e convenções sociais esperadas à pessoa outorgada de um determinado sistema sexo-gênero no nascimento ou gestação (MARANHÃO Fo, 2014).

17 Acerca da questão do uso do nome social para pessoas transexuais e travestis como paliativo, leia: MARANHÃO Fo, $2012 a$ e $2013 b$.

18 Sobre o "Projeto Escola sem Partido", esse diz respeito ao Projeto de Lei $\mathrm{n}^{\mathrm{o}}$ 867, de 2015 apresentado à Câmara dos Deputados pelo Sr. Izalci, e visa incluir entre as diretrizes e bases da educação nacional o Programa Escola sem Partido, no qual fica "vedada, em sala de aula, a prática de doutrina política e ideológica bem como a veiculação de conteúdos ou a realização de atividades que possam estar em conflito com as convicções religiosas ou morais dos pais ou responsáveis pelos estudantes” (art. $3^{\circ}$ ), para além disso, o artigo $4^{\circ}$ prevê que o professor "não fará propaganda político-partidária em sala de aula nem incitará seus alunos a participar de manifestações, atos públicos e passeatas". Nesse sentido, o professor fica impedido de construir em sala de aula qualquer tipo de dialogo que vise fomentar o exercício da cidadania e a participação em 
movimentos de luta por direitos por parte das/os estudantes.

19 No que tange a essa questão da "ideologia de gênero", Scott cita que esse termo foi utilizado como oposição a um manual de instrução que foi criado na França para preparar estudantes para os exames de bacharelado em ciências biológicas e que foi aprovado pelo Ministério da Educação, o qual incluía uma unidade em biologia humana intitulada "Devenir Homme ou Femme" (Tornarse Homem ou Mulher), foi aí que a antiga senadora e também porta-voz do Vaticano chamada Christine Boutin escreveu uma carta aberta para o Ministério de Educação que denunciava “a pedagogia direta e explicitamente inspirada na teoria de gênero", considerando essa teoria como uma ideologia que não pertence ao currículo da ciência porque estaria negando a realidade da diferente de mulher para homem, conjurando um tipo de "marxismo bicho-papão" (SCOTT, 2012, p.239). Após o pronunciamento de Boutin houve uma petição assinada por mais de cem deputados e senadores que exigiam a retratação do manual, além de uma campanha on-line que reuniu milhares de assinaturas para exigir respeito pela liberdade de consciência religiosa e condenando um ensino que estaria corrompendo seus filhos adolescente sugerindo que eles tiveram uma escolha sobre as suas sexualidades (SCOTT, 2012).

\section{REFERÊNCIAS BIBLIOGRÁFICAS}

Abaixo-assinado Somos contra o maior escândalo deste País, o KIT GAY in Petição Pública. Disponível em: http://www.peticaopublica.com.br/?pi=PROL. Acesso em: nov. 2014.

ABHR, Comissão de Direitos Humanos. Carta da ABHR contra o golpe, pela democracia e legalidade (março de 2016). Disponível em: $<$ www.abhr.org.br $>$.

ABHR, Comissão de Direitos Humanos. Nota de repúdio da ABHR à apologia à tortura em declaração de Jair Bolsonaro (19 de abril de 2016). Disponível em: <www.abhr.org.br>.
AMORIM, Felipe; PRAZERES, Leandro; MARCHESAN, Ricardo. Ministro de Temer justifica ausência de mulheres no governo: "não foi possível”. In: UOL Notícilas Política. Públicação de 13 de maio de 2016.

ARAUJO, Glauco. Grampo em conversa com Dilma é 'arbitrariedade', diz adrogado de Lula (15/03/2016). Disponivel em: $\quad$ http://g1.globo.com/saopaulo/noticia/2016/03/divulgacao-de-audio-de-lula-edilma-estimula-convulsao-social-diz-advogado.html

BARBOSA, Erivaldo Moreira; MACHADO, Charliton José dos Santos. Gênese do direito do voto feminino no Brasil: Uma análise jurídica, política e educacional. Revista HISTEDBR On-line. Campinas, n. 45, 2012. pp. 89-100.

BLAY, Eva Alterman. 8 de março: Conquistas e controvérsias. Estudos Feministas. Ano 9, 2001. pp. 601-607.

BRASIL 247. TEMER VETA PALAVRA "PRESIDENTA" EM PUBLICAÇÕES DA EBC. In: BRASIL 247. Edição [online] de 31 de maio de 2016

BRASIL. LEI $n^{\circ} 4.121$, de 27 de agosto de 1962. CAMARA DOS DEPUTADOS. Projeto de LEI $n^{\circ}$ 867 , de 2015 .

DIAS, Adriana. Estupro coletivo no Rio de Janeiro: Pesquisa no perfil de mídias sociais dos 33 acusados revela que 14 se identificam como evangélicos. In: Mídia, Religião e Política. Edição [online] de 02 de junho de 2016.

DUARTE, Constância Lima. Feminismo e literatura no Brasil. Estud. av. [online]. vol.17, n. 49, 2003. pp. 151-172.

FOLHA DE SÃO PAULO. Em 91, Collor disse que tinha nascido com "aquilo roxo" (29 mar. 1996). Disponível $\mathrm{em}$ http://www 1.folha.uol.com.br/fsp/1996/3/29/br asil/4.html

FOLHA DE SÃO PAULO. Veja frases dos deputados durante a votação do impeachment. In: Folha de São Paulo. Edição [online] de 17 de abril de 2016.

IPEA. Sistema de Indicadores de Percepção Social: Tolerância social à Violência contra as mulheres. Brasília: Governo Federal, 2014, p. 1-40. Disponível em: <http://www.ipea.gov.br/portal/images/stories/ PDFs/SIPS/140327_sips_violencia_mulheres.pdf $\geq$. 
LINHARES, Juliana. Marcela Temer: bela, recatada e "do lar". In: Revista Veja. São Paulo: Editora Abril. Edição de 18 de abril de 2016.

MARANHÃO $\mathrm{F}^{\mathrm{o}}$, Eduardo Meinberg de Albuquerque. A grande onda vai te pegar: Marketing, espetáculo e ciberespaço na Bola de Neve Church. São Paulo: Fonte Editorial, 2013a.

Anotações sobre a "inclusão" de travestis e transexuais a partir do nome social e mudança de prenome. In: MARANHÃO $\mathrm{F}^{\circ}$, Eduardo Meinberg de Albuquerque (Org.). Dossiê (In) Visibilidade Trans 1. História Agora, São Paulo, v.1, n. 15, pp. 29-59, $2013 b$.

"Inclusão" de travestis e transexuais através do nome social e mudança de prenome: diálogos iniciais com Karen Schwach e outras fontes. Oralidades - Revista de História Oral da USP, dossiê Diversidades e Direitos, pp. 89-116, $2012 a$.

"Nós somos a dobradiça da porta": notas preliminares sobre as mulheres na Bola de Neve Church. In: SOUZA, Sandra Duarte de (org.). Mandrágora, v. 18, n. 18, pp. 81-106, $2012 b$.

A Pomba-gira Lady Gaga e a travesti indígena: (Re/des) fazendo gênero no Alto Rio Negro. In: Mouseion (UniLasalle), v. 22, pp. 151$175,2015 a$.

"Educar corretamente evitando aberrações”: discursos punitivos / discriminatórios sobre homossexualidades e transgeneridades. In: Paralellus, Recife, v. 6, n. 12, pp. 187-200, jan./jun. $2015 b$.

“É prá baixar o porrete!” Notas iniciais sobre discursos punitivos- discriminatórios acerca das homossexualidades e transgeneridades. In: Mandrágora, São Bernardo do Campo, v. 21, n. 21 , pp. $47-87,2015 c$.

(Re/des)conectando gênero e religião. Peregrinações e conversões trans* e ex-trans* em narrativas orais e do Facebook. Tese de Doutorado apresentada ao Programa de Pós Graduação em História Social da Universidade de São Paulo. São Paulo, 2014.

Sai desse corpo que esse caminho não te pertence! Pessoas trans* e ex-trans* em (re/des)caminhos de gênero, corpo e alma. In: Revista Brasileira de História das Religiões. ANPUH, Ano VIII, n. 24, p. 197-219, Janeiro/Abril de 2016.
MATOSO, Filipe. Transexuais e travestis poderão usar nome social no serviço público federal (28 abril 2016). Disponível em: http://g1.globo.com/politica/noticia/2016/04/dilmaautoriza-gays-usar-nome-social-no-servico-publicofederal.html.

MÍDIA, RELIGIÃO E POLÍTICA. Nova secretária de Mulheres do governo interino é evangélica e contra o aborto até em caso de estupro. Pressionada, relativizou posição. . In: Mídia, Religião e Política. Edição [online] de o2 de junho de 2016.

MORAIS, Raquel. Morre Brilhante Ustra, ex-chefe do DOI-Codi durante a ditadura (15/10/2015). Disponível em: http://g1.globo.com/distrito-

federal/noticia/2015/10/morre-brilhante-ustra-ex-chefe-deorgao-de-repressao-na-ditadura.html

NARVAZ, Martha Giudice; KOLLER, Silvia Helena. Famílias e patriarcado: da prescrição normativa à subversão criativa. Psicologia $\xi^{2}$ Sociedade. Vol. 18, n. 1, 2006. pp. 49-55.

PEREIRA JUNIOR, Luiz Costa. Presidente ou presidenta? Língua Portuguesa (dezembro de 2011). Disponível

em $<$ http://revistalingua.com.br/textos/62/presidente-oupresidenta-248988-1.asp $>$.

RAMOS, Jair de Souza. A sexualidade como campo de batalha na internet: grupos religiosos $\mathrm{e}$ movimentos feministas e LGBT na luta em torno dos direitos sexuais. In: 29a Reunião Brasileira de Antropologia, 2014.

REVISTA ISTOÉ. Capa: As explosões nervosas da Presidente. In: Revista ISTOÉ. São Paulo: Editora Três. Edição 2417, abril de 2016.

SCOTT, Joan. Os usos e abusos do gênero. In: Projeto História, São Paulo, n. 45, 2012. pp. 327-351.

SILVA. Eliane Moura da. Fundamentalismo evangélico e questões de gênero: em busca de perguntas. In: SOUZA, Sandra Duarte (org.). Gênero e Religião no Brasil: Ensaios Feministas. São Bernardo do Campo: Universidade Metodista de São Paulo, 2006. pp.10-43.

VEJA São Paulo (01 set. 2015). Anúncio de adesivo com montagem de Dilma foi feito por uma mulher. Disponível em: http://vejasp.abril.com.br/blogs/cidade/adesivo-commontagem-de-presidente-dilma-causa-revolta-nainternet/

WILLMERSDORF, Pedro. Deputados protocolam projeto para impedir transexuais e travestis de usarem nome social. Disponível em: http://extra.globo.com/noticias/brasil/deputadosprotocolam-projeto-para-impedir-transexuais-travestis-deusarem-nome-social-19337984.html\#ixzz4AAvoDoaM. 
THE HYSTERICAL AND THE BEAUTIFUL, DEMURE AND HOMELY: MISOGYNY TO DILMA ROUSSEFF IN THE CONCEPTION OF WOMEN AS RIB AND MEN AS HEAD OF BRAZILIAN POLITICS

ABSTRACT: tHIS ARTICLE PRESENTS SOME REFLECTIONS ON THE MISOGYNIST ATTACKS BRANDISHED AGAINST THE FIRST FEMALE PRESIDENT OF BRAZIL, DILMA ROUSSEFF, WHO IS CURRENTLY SUFFERING AN IMPEACHMENT PROCESS. SHE WAS REPLACED BY AN INTERIM GOVERNMENT THAT, ACCOMPANIED BY A PARCEL OF THE MEDIA VEHICLES IN THE COUNTRY, REPRESENTS A CONSERVATIVE IMAGE OF THE ROLE OF WOMEN IN POLITICS AND BRAZILIAN SOCIETY. THIS IDEAL WOMAN Standard, ACCORDING tO REACTIONARY VISION CAN BE SUMMARIZED BY "BEAUTIFUL, WELl BEHAVEd AND HOUSEWIFELY" WHILE DILMA, TO THOSE WHO WANT TO CRITICIZE THE POLITICAL VISION OR THE GOVERNMENT RECEIVES ADJECTIVES LIKE "UGLY", "HYSTERICAL” OR "BITCH”.

KEY-WORDS: DILMA ROUSSEFF AND MISOGYNY; MICHEL TEMER AND CONSERVATISM; GENDER, RELIGION, MEDIA AND POLITICS.

LA HISTÉRICA Y LAS BELLAS, RECATADAS Y DEL HOGAR: MISOGINIA A DILMA ROUSSEFF, CON BASE EN LA COMPRENSIÓN DE LAS MUJERES COMO LA COSTILLA Y LOS HOMBRES COMO LA CABEZA DE LA POLIITICA BRASILEÑA

RESUMEN: PRESENTAMOS EN ESE ARTíCULO ALGUNAS REFLEXIONES ACERCA DE LOS ATAQUES MISÓGINOS PERPETRAdOS A La PRIMERA PRESIDENTA DE BRASIL, DILMA ROUSSEFF, QUE ACTUALMENTE SUFREN PROCESO DE JUICIO POLÍTICO, FUE SUSTITUIDO POR UN GOBIERNO INTERINO QUE, ASI COMO PARTE DE LOS VEHÍCULOS DE COMUNICACIÓN EN EL PÁS, REPRESENTA UNA CONCEPCIÓN CONSERVADORA DE LA FUNCIÓN DE LA MUJER EN LA POLÍTICA Y LA SOCIEDAD BRASILEÑA. ESA NORMA MUJER IDEAL, SEgÚN LA VISIÓN REACCIONARIA SE PUEDE RESUMIR EN "hERMOSA, RECATADA Y EL hOGAR", MIENTRAS QUE DILMA, A LOS QUE QUIEREN CRITICAR la VISIÓN POLÍTICA $O$ EL GOBIERNO RECIBE ADJETIVOS COMO "PERRA, HISTÉRICA, FEA ".

PALABRAS Clave: DILMA ROUSSEFF Y LA MISOGINIA; MICHEL teMER Y EL CONSERVADURISMO; EL GÉNERO, LA RELIGIÓN, LOS MEDIOS DE COMUNICACIÓN Y LA POLITICA. 